\title{
Effectiveness and safety of ombitasvir/ paritaprevir/ritonavir in treatment of chronic hepatitis C Egyptian hemodialysis patients, case-control study
}

\author{
Nahla Mohamed Teama ${ }^{1 *}$, Waleed Anwar Abdel-Mohsen ${ }^{1}$, Ossama Ashraf Ahmed²,
} Sarah Mohamed El Sayed ${ }^{1}$ and Ahmed Mohamed ElGhandour ${ }^{2}$

\begin{abstract}
Background: Prevalence of hepatitis C virus infection in patients with renal diseases is higher compared to the general population. FDA has approved ombitasvir/paritaprevir/ ritonavir for the treatment of patients with severe renal disease. This study aimed to evaluate the efficacy and safety of ombitasvir/paritaprevir/ritonavir with or without ribavirin in treatment of chronic hepatitis C Egyptian hemodialysis patients to compare it with the same treatment result in chronic hepatitis C Egyptian patients with normal renal functions. This case-control study was conducted on one hundred patients with confirmed diagnosis of HCV-positive infection at the Center of National Committee for Control of Viral Hepatitis [NCCVH] at Ain Shams University Hospital. Patients were divided into two groups: group I (control group) with 50 chronic hepatitis C virus patients with normal renal functions and group II (Case Group) with 50 chronic hepatitis $C$ virus hemodialysis patients.
\end{abstract}

Results: $95.1 \%$ of prevalent hemodialysis patients achieved sustained virological response (SVR), while 100\% of patients with normal kidney functions achieved sustained virological response. Most common side effects were hemoglobin drop, gastrointestinal disturbance, severe fatigue, and itching.

Conclusion: Ombitasvir, paritaprevir, and ritonavir are considered a safe and effective in treatment in HCV infection in patients on regular hemodialysis as in chronic hepatitis $C$ virus infection patients with normal kidney functions.

Keywords: Ombitasvir, Paritaprevir, Ritonavir, Ribavirin chronic hepatitis C, Hemodialysis

\section{Background}

Hepatitis $\mathrm{C}$ virus infection is a major global health problem. Over 80 million are estimated to be chronically infected throughout the world, with 3-4 million new infections and 350,000 deaths occurring due to HCVrelated complications such as cirrhosis and hepatocellular carcinoma annually [1]. Egypt's prevalence of infection with hepatitis $\mathrm{C}$ virus (HCV) is the highest in the globe. The high prevalence is mainly due to the

\footnotetext{
*Correspondence: nahlateama@med.asu.edu.eg

'Department of Internal Medicine and Nephrology, Faculty of Medicine, Ain

Shams University, Ramsis 38 Street, Abassia, Cairo 11211, Egypt

Full list of author information is available at the end of the article
}

parenteral antischistosomal therapy campaigns that were conducted between the 1950s and the 1980s in which more than 6 million individuals received 36 million injections, almost all with shared unsterilized syringes and needles. This is the greatest iatrogenic spread of bloodborne infection ever to occur [2]. Direct-acting antivirals (DAAs) transformed HCV management into a curable disease. The use of standard interferon-based therapies was correlated with low efficacy and elevated toxicity in patients with elevated renal functions. Recent advancement of DAAs has dramatically altered the treatment of chronic hepatitis $\mathrm{C}$ and interferon-free regimens have become the preferred therapy in clinical practice [3]. 
Three direct-acting antiviral (3D) regimen is an alloral interferon-free combination of the protease inhibitor paritaprevir co-formulated with ritonavir as a systemic PK enhancer and the nonstructural protein 5A (NS5A) inhibitor ombitasvir [4].

Recently, the FDA has endorsed ombitasvir/paritaprevir/ ritonavir (OBV/PTV/ RITONA) for treatment of patients with severe renal disease. Metabolism of these compounds is mediated mainly by the liver. Treatment with OBV/PTV/RITONA \pm RBV is currently approved for patients infected with $\mathrm{HCV}$, based on the results of several clinical trials in which sustained virological response (SVR) rates at week 12 (SVR12) reached 95$100 \%$ [5].

The aim of this study was to evaluate the efficacy and safety of ombitasvir/paritaprevir/ritonavir with or without ribavirin in treatment of chronic hepatitis C Egyptian hemodialysis patients and compare it with the same treatment result in chronic hepatitis C Egyptian patients with normal renal functions.

\section{Methods}

This study was performed in accordance with the ethical standards of Ain Shams University Research Committee and with the 1964 Helsinki Declaration and its later amendments or comparable ethical standards. Ethics committee's reference number is 00017585 .

Written informed consent was obtained from all individual participants included in the study. Informed consent to publish patient's data was signed by all participants prior to the beginning of the research.

\section{Patient selection}

One hundred patients were enrolled in this study and were selected from the Center of National Committee for Control of Viral Hepatitis [NCCVH] in Ain Shams University Hospital. All patients with chronic hepatitis C were treated with ombitasvir/paritaprevir/ritonavir with or without ribavirin during the period between May 2018 and December 2018.

\section{Study design}

The patients were assigned into 2 groups:

Group I (control group): Fifty chronic hepatitis C virus patients with normal renal functions as assessed by serum creatinine and by calculation of GFR. All patients in this group received ombitasvir/paritaprevir/ ritonavir with ribavirin $[1000 / 1200 \mathrm{mg}$ on the basis of bodyweight $\leq 75 />75 \mathrm{~kg}$.

Group II (case group): Fifty chronic hepatitis C virus infection prevalent hemodialysis patients for more than 6 months; these patients received conventional hemodialysis 3 sessions per week each $4 \mathrm{~h}$ long using standard dialysate containing bicarbonate and biocompatible hemodialysis (HD) membrane and heparin as an anticoagulant; they received ombitasvir/ paritaprevir/ritonavir with ribavirin at a dose of $200 \mathrm{mg}$ three times/week, $4 \mathrm{~h}$ before session of hemodialysis. Ribavirin was stopped when hemoglobin level less than $8.5 \mathrm{gm} / \mathrm{dl}$.

All patients in the drug and control groups were subjected to the following: full history, full clinical examination, and laboratory investigations before treatment including liver function tests (alanine transaminase (ALT), aspartate transaminase (AST), total bilirubin, serum albumin, hepatitis B surface antigen (HBsAg), Alpha Fetoprotein (AFP), HCV PCR quantitative), serum creatinine, hemoglobin A1c (HbA1c), complete blood picture $(\mathrm{CBC})$, and pelvi-abdominal ultrasound. Laboratory investigations during treatment included AST, ALT, total bilirubin, serum albumin, serum creatinine, international normalized ratio (INR), and $\mathrm{CBC}$. Laboratory investigations after treatment were HCV PCR quantitative at week 16 and 24 from start of treatment.

All patients were subjected to regular follow-up monthly visits at NCCVH at Ain Shams University Hospitals and side effects were detect during these visits and in between monthly visits by telephone or extra visits if needed.

Patients with ages less than 18 , chronic hepatitis B, decompensated liver cirrhosis [child $\mathrm{C}$ ], severe anemia (hemoglobin level less than $10 \mathrm{gm}$ ), known HCC or other malignancy or known cardiac or neuropsychiatric disease were excluded from the study.

\section{Statistical analysis}

Data were collected, revised, coded, and entered to the Statistical Package for Social Science (IBM SPSS) version 23. The quantitative data were presented as mean, standard deviations, and ranges when their distribution was found to be parametric and median with interquartile range (IQR) when their distribution was found to be non-parametric. Also, qualitative variables were presented as number and percentages. The comparison between groups regarding qualitative data was done using Chi-square test. The comparison between two independent groups with quantitative data and parametric distribution were done using Independent $t$ test while data with non-parametric distribution were done using Mann-Whitney test. The comparison between more than two paired groups with quantitative data and parametric distribution were done using repeated measure ANOVA test, while comparison between more than two paired groups with quantitative data and non-parametric distribution was done using Friedman test. The confidence 
interval was set to $95 \%$ and the margin of error accepted was set to $5 \%$.

So, $p$ value was considered significant as the following: $p$ value $<0.05$, significant $(\mathrm{S})$

\section{Results}

This study included 100 patients divided into two groups. Group I included 50 patients; 35 males and 15 females with mean age 47 years. Five patients had hypertension and eight patients had diabetes mellitus. Group II included 50 patients, 30 males and 20 females with mean age 51 years. Twenty-five patients had hypertension and 14 patients had diabetes. All patients were naïve to antiviral treatment.

Of 100 participants, 91 patients completed the course of treatment, six patients stopped treatment due to adverse effects, two patients died during the course of treatment, and one patient died after the course of treatment but before performing $\mathrm{HCV}$ PCR quantitative at week sixteen of treatment.

95.1\% of prevalent hemodialysis patients achieved cure which means they achieved sustained virological response (SVR), while $100 \%$ of patients with normal kidney functions achieved sustained virological response. The most common side effects were hemoglobin drop, gastrointestinal disturbance, severe fatigue, and itching.

Table 1 shows that $95.1 \%$ of hemodialysis patients and $100 \%$ of control group achieved end of treatment response and sustained virologic response. There was no statistically significant difference between two groups regarding the cure rate.

There was highly statistically significant differences between the two groups regarding presence of gastrointestinal (GIT) symptoms which includes nausea, vomiting, and GIT upset with $p$ value of 0.006 and statistically significant difference between two groups regarding patients that stopped treatment during course due to severe anemia and sever fatigue with $p$ value of 0.012 (Table 2). There was statistically significant difference between two groups regarding patients needed blood transfusion during treatment with $p$ value of 0.022 and no statistical difference between two groups regarding itching and sever fatigue; no statically significant difference between the two groups regarding death rate. Three patients died during the course of treatment, 2

Table 1 Comparison between group I (control group) and group II (case group) regarding cure rate after treatment

\begin{tabular}{lllll}
\hline Cure & $\begin{array}{l}\text { Group I } \\
\text { No. }=\mathbf{5 0}\end{array}$ & $\begin{array}{l}\text { Group II } \\
\text { No. }=\mathbf{4 1}\end{array}$ & $\begin{array}{l}\text { Test } \\
\text { value* }\end{array}$ & $\begin{array}{l}\boldsymbol{p} \\
\text { value }\end{array}$ \\
\hline Complete & $50(100.0 \%)$ & $39(95.1 \%)$ & 2.494 & 0.114 \\
Relapse & $0(0.0 \%)$ & $2(4.9 \%)$ & & \\
\hline
\end{tabular}

${ }^{*}$ Chi-square test
Table 2 Comparison between group I (control group) and group II (case group) regarding complications occurred during the course of treatment

\begin{tabular}{|c|c|c|c|c|c|c|}
\hline & \multicolumn{2}{|c|}{ Group I } & \multicolumn{2}{|c|}{ Group II } & \multirow{2}{*}{$\begin{array}{l}\text { Test } \\
\text { value }^{a}\end{array}$} & \multirow{2}{*}{$\begin{array}{l}p \\
\text { value }\end{array}$} \\
\hline & No. & $\%$ & No. & $\%$ & & \\
\hline Patient stopped treatment & 0 & 0.0 & 6 & 12.0 & 6.383 & 0.012 \\
\hline Death & 0 & 0.0 & 3 & 6.0 & 3.093 & 0.079 \\
\hline Blood transfusion & 0 & 0.0 & 5 & 10.0 & 5.263 & 0.022 \\
\hline Itching & 0 & 0.0 & 2 & 4.0 & 2.041 & 0.153 \\
\hline Sever fatigue & 0 & 0.0 & 3 & 6.0 & 3.093 & 0.079 \\
\hline Gastrointestinal symptoms & 0 & 0.0 & 7 & 14.0 & 7.527 & 0.006 \\
\hline
\end{tabular}

${ }^{a}$ Chi-square test

patients had sudden death, and 1 patient died due to cerebral hemorrhage despite normal platelet level and normal INR.

There is a difference in hemoglobin, albumin, and creatinine levels between dialysis and normal group with high statistically significant difference ( $p$ value, 0.001 ), but there is no significant change in AST, ALT, total bilirubin, INR, and platelet levels.

There is a difference in hemoglobin, total bilirubin, and creatinine levels between dialysis and normal group with high statistically significant difference ( $p$ value 0.001 ); there is statistical difference in albumin and platelet levels with $p$ value of 0.028 , but there is no significant change in AST, ALT, and INR.

There is a difference in hemoglobin, total bilirubin, and creatinine levels between dialysis and normal group with high statistically significant difference ( $p$ value, $0.001)$; there is statistical difference in albumin level with $p$ value of 0.030 .

There is a difference in hemoglobin, albumin, and creatinine levels between the dialysis and normal group with high statistically significant difference ( $p$ value, $0.001)$; there is statistically difference in total bilirubin level with $p$ value of 0.047 , but there is no significant change in AST, ALT, INR, and platelet levels.

From Tables 3, 4, 5, and 6, there is a decrease in hemoglobin level along the treatment course with high statistically significant difference ( $p$ value, 0.001 ), a decrease in AST and ALT levels along the course of treatment with high statistically significant difference ( $p$ value, 0.001 ) and there is increase at total bilirubin level with high statistically significant difference ( $p$ value, 0.001 ), but there is no significant change in albumin, INR, platelet, and creatinine levels during the course of treatment.

Also, from the Tables 3, 4, 5, and 6, there is a decrease in hemoglobin level along the treatment course in the case group with high statistically significant difference ( $p$ value, 0.001), a decrease in AST and ALT level along the course of treatment with high statistically significant difference ( $p$ value, 0.001 ), and an increase at total bilirubin level and INR with 
Table 3 Comparison between group I (control group) and group II (case group) regarding levels of hemoglobin, AST, ALT, albumin, total bilirubin, INR, platelets, and creatinine before start of treatment

\begin{tabular}{|c|c|c|c|c|c|}
\hline & & Group I & Group II & Test value & $p$ value \\
\hline \multirow[t]{2}{*}{ Hemoglobin (gm/dl) } & Mean \pm SD & $14.56 \pm 1.72$ & $12.09 \pm 1.75$ & 7.111 & 0.001 \\
\hline & Range & $10.8-17.6$ & $10-16.4$ & & \\
\hline \multirow[t]{2}{*}{ AST (U/L) } & Normal & $31(62.0 \%)$ & 37 (74\%) & 1.654 & 0.198 \\
\hline & High & 19 (38.0\%) & $13(26 \%)$ & & \\
\hline \multirow[t]{2}{*}{ ALT (U/L) } & Normal & 31 (62\%) & 35 (70\%) & 0.407 & 0.523 \\
\hline & High & $19(38 \%)$ & $15(30 \%)$ & & \\
\hline \multirow[t]{2}{*}{ Albumin (gm/dl) } & Mean \pm SD & $4.28 \pm 0.41$ & $4.03 \pm 0.37$ & 3.253 & 0.002 \\
\hline & Range & $2.6-5$ & $3.1-5.1$ & & \\
\hline \multirow[t]{2}{*}{ Bilirubin (mg/dl) } & Mean \pm SD & $0.65 \pm 0.24$ & $0.58 \pm 0.19$ & 1.610 & 0.111 \\
\hline & Range & $0.2-1.4$ & $0.19-1$ & & \\
\hline \multirow[t]{2}{*}{ INR } & Mean \pm SD & $1.09 \pm 0.09$ & $1.12 \pm 0.11$ & -1.675 & 0.097 \\
\hline & Range & $0.9-1.3$ & $0.89-1.4$ & & \\
\hline \multirow[t]{2}{*}{ Platelets $\left(10^{3} / \mathrm{mm}^{3}\right)$} & Mean \pm SD & $233.88 \pm 67.28$ & $215.18 \pm 67.56$ & 1.387 & 0.169 \\
\hline & Range & $94-400$ & $108-372$ & & \\
\hline \multirow[t]{2}{*}{ Creatinine (mg/dl) } & Median (IQR) & $0.85(0.8-0.91)$ & $7.3(6.1-9.49)$ & -8.631 & 0.001 \\
\hline & Range & $0.5-1.3$ & $3.6-12.75$ & & \\
\hline
\end{tabular}

statistically significant difference ( $p$ value, 0.034 , and $p$ value, 0.017 , respectively) but there is no significant change in albumin, total bilirubin, platelet, and creatinine levels during the course of treatment.

\section{Discussion}

Egypt used to be on the top of the countries with heavy HCV burden. Treatment of HCV in Egypt has become one of the top national priorities since 2007. Egypt started a national treatment program intending to provide cure for Egyptian $\mathrm{HCV}$-infected patients. Mass $\mathrm{HCV}$ treatment program had started using pegylated interferon and ribavirin between 2007 and 2014. Yet, with the development of highly effective direct-acting antivirals (DAAs) for HCV, elimination of viral hepatitis has become a real possibility. Egypt adopted a strategy

Table 4 Comparison between group I (control group) and group II (case group) regarding levels of hemoglobin, AST, ALT, albumin, total bilirubin, INR, platelets, and creatinine 4 weeks after treatment

\begin{tabular}{|c|c|c|c|c|c|}
\hline & & Group I & Group II & Test value & $p$ value \\
\hline \multirow[t]{2}{*}{ Hemoglobin $(\mathrm{gm} / \mathrm{dl})$} & Mean \pm SD & $12.63 \pm 1.59$ & $10.27 \pm 1.97$ & 6.581 & 0.001 \\
\hline & Range & $8.8-16$ & $7.1-15.1$ & & \\
\hline \multirow[t]{2}{*}{ AST (U/L) } & Normal & 49 (98.0\%) & 47 (94\%) & 1.042 & 0.307 \\
\hline & High & $1(2 \%)$ & $3(6 \%)$ & & \\
\hline \multirow[t]{2}{*}{ ALT (U/L) } & Normal & 45 (90\%) & 47 (94\%) & 0.543 & 0.461 \\
\hline & High & $5(10 \%)$ & $3(6 \%)$ & & \\
\hline \multirow[t]{2}{*}{ Albumin (gm/dl) } & Mean \pm SD & $4.26 \pm 0.40$ & $4.03 \pm 0.57$ & 2.261 & 0.026 \\
\hline & Range & $3.2-5.4$ & $2.7-5.3$ & & \\
\hline \multirow[t]{2}{*}{ Bilirubin (mg/dl) } & Mean \pm SD & $0.99 \pm 0.43$ & $0.73 \pm 0.33$ & 3.324 & 0.001 \\
\hline & Range & $0.2-2$ & $0.2-2$ & & \\
\hline \multirow[t]{2}{*}{ INR } & Mean \pm SD & $1.08 \pm 0.13$ & $1.05 \pm 0.08$ & 1.197 & 0.234 \\
\hline & Range & $1-1.65$ & $0.9-1.21$ & & \\
\hline \multirow[t]{2}{*}{ Platelets $\left(10^{3} / \mathrm{mm}^{3}\right)$} & Mean \pm SD & $250.27 \pm 92.85$ & $213.56 \pm 69.12$ & 2.234 & 0.028 \\
\hline & Range & $132-663$ & $92-430$ & & \\
\hline \multirow[t]{2}{*}{ Creatinine (mg/dl) } & Median (IQR) & $0.88(0.7-0.95)$ & $7.38(5.6-9)$ & -8.634 & 0.001 \\
\hline & Range & $0.3-1.2$ & $3-16.8$ & & \\
\hline
\end{tabular}


Table 5 Comparison between group I (control group) and group II (case group) regarding levels of hemoglobin, AST, ALT, albumin, total bilirubin, INR, platelets, and creatinine 8 weeks after treatment

\begin{tabular}{|c|c|c|c|c|c|}
\hline & & Group I & Group II & Test value & $p$ value \\
\hline \multirow[t]{2}{*}{ Hemoglobin (gm/dl) } & Mean \pm SD & $12.53 \pm 1.35$ & $9.43 \pm 1.75$ & 9.763 & 0.001 \\
\hline & Range & $9.8-15.5$ & $6.4-13$ & & \\
\hline \multirow[t]{2}{*}{ AST (U/L) } & Normal & $50(100 \%)$ & $46(100 \%)$ & 0.930 & 0.335 \\
\hline & High & $0(0 \%)$ & $0(0 \%)$ & & \\
\hline \multirow[t]{2}{*}{ ALT (U/L) } & Normal & 49 (98\%) & $46(100 \%)$ & 0.930 & 0.335 \\
\hline & High & $1(2 \%)$ & $0(0 \%)$ & & \\
\hline \multirow[t]{2}{*}{ Albumin (gm/dl) } & Mean \pm SD & $4.18 \pm 0.39$ & $3.97 \pm 0.54$ & 2.202 & 0.030 \\
\hline & Range & $2.6-5.1$ & $2-5.4$ & & \\
\hline \multirow[t]{2}{*}{ Bilirubin (mg/dl) } & Mean \pm SD & $0.90 \pm 0.42$ & $0.62 \pm 0.24$ & 3.848 & 0.001 \\
\hline & Range & $0.3-2.08$ & $0.1-1.39$ & & \\
\hline \multirow[t]{2}{*}{ INR } & Mean \pm SD & $1.11 \pm 0.16$ & $1.10 \pm 0.13$ & 0.618 & 0.538 \\
\hline & Range & $0.95-2$ & $0.67-1.4$ & & \\
\hline \multirow[t]{2}{*}{ Platelets $\left(10^{3} / \mathrm{mm}^{3}\right)$} & Mean \pm SD & $234.44 \pm 65.96$ & $225.95 \pm 68.82$ & 0.610 & 0.543 \\
\hline & Range & $135-439$ & $105-400$ & & \\
\hline \multirow[t]{2}{*}{ Creatinine (mg/dl) } & Median (IQR) & $0.9(0.8-1)$ & $7(5.9-9.1)$ & -8.310 & 0.001 \\
\hline & Range & $0.6-1.2$ & $3.5-13.8$ & & \\
\hline
\end{tabular}

that represents a model of care that could help other countries with high HCV prevalence rate in their battle against HCV Omran et al. [6].

The results of our study revealed that $95.1 \%$ of prevalent hemodialysis patients achieved SVR12 to the combination of ombitasvir/paritaprevir/ritonavir but treatment failure was observed in $4 \%$ of patients. Most of patients tolerated treatment; only 6 patients $(12 \%)$ discontinued treatment due to side effects including severe anemia, fatigue, and GIT intolerance. In our study, three patients died during the treatment course. The most common side effects were anemia in $5(10 \%)$ patients, requiring blood transfusion; gastrointestinal disturbance including nausea and

Table 6 Comparison between group I (control group) and group II (case group) regarding levels of hemoglobin, AST, ALT, albumin, total bilirubin, INR, platelets, and creatinine 12 weeks after treatment

\begin{tabular}{|c|c|c|c|c|c|}
\hline & & Group I & Group II & Test value & $p$ value \\
\hline \multirow[t]{2}{*}{ Hemoglobin } & Mean \pm SD & $12.36 \pm 1.62$ & $8.92 \pm 1.63$ & 10.021 & 0.001 \\
\hline & Range & $8.8-15.7$ & $4.2-12.4$ & & \\
\hline \multirow[t]{2}{*}{ AST (U/L) } & Normal & $50(100 \%)$ & $40(95.2 \%)$ & 2.434 & 0.119 \\
\hline & High & $0(0 \%)$ & $2(4.8 \%)$ & & \\
\hline \multirow[t]{2}{*}{ ALT (U/L) } & Normal & $50(100 \%)$ & $40(95.2 \%)$ & 2.434 & 0.119 \\
\hline & High & $0(0 \%)$ & $2(4.8 \%)$ & & \\
\hline \multirow[t]{2}{*}{ Albumin (gm/dl) } & Mean \pm SD & $4.25 \pm 0.35$ & $3.89 \pm 0.41$ & 4.682 & 0.001 \\
\hline & Range & $3.5-5.1$ & $2.9-4.8$ & & \\
\hline \multirow[t]{2}{*}{ Bilirubin (mg/dl) } & Mean \pm SD & $0.87 \pm 0.43$ & $0.70 \pm 0.33$ & 2.019 & 0.047 \\
\hline & Range & $0.3-2.6$ & $0.1-1.9$ & & \\
\hline \multirow[t]{2}{*}{ INR } & Mean \pm SD & $1.09 \pm 0.08$ & $1.08 \pm 0.11$ & 0.592 & 0.555 \\
\hline & Range & $1-1.26$ & $0.88-1.36$ & & \\
\hline \multirow[t]{2}{*}{ Platelets $\left(10^{3} / \mathrm{mm}^{3}\right)$} & Mean \pm SD & $242.57 \pm 69.99$ & $233.35 \pm 91.59$ & 0.538 & 0.592 \\
\hline & Range & $155-501$ & $114-570$ & & \\
\hline \multirow[t]{2}{*}{ Creatinine (mg/dl) } & Median(IQR) & $0.9(0.8-1)$ & $7(5.87-8.9)$ & -8.051 & 0.001 \\
\hline & Range & $0.6-1.2$ & $3.6-12.8$ & & \\
\hline
\end{tabular}


vomiting in 7 patients (14\%); severe fatigue in $3(6 \%)$ patients; and itching in $2(4 \%)$ patients.

The three patients that died during the course of treatment 2 patients had sudden death and 1 patient died due to cerebral hemorrhage despite normal platelet level and normal INR.

During the course of treatment, our study showed that patient had hemoglobin level drop, AST and ALT level improvement, increase at bilirubin level, and no change at albumin level, platelet level, total leukocyte count, and creatinine level.

Similar to our study, Liu et al. [7] investigated paritaprevir/ritonavir/ombitasvir for East-Asian non-cirrhotic hepatitis $C$ virus patients receiving hemodialysis. Their study sample included 46 patients. The primary efficacy endpoint was sustained virologic response 12 weeks offtherapy $\left(S R_{12}\right.$ ). The $S_{V R}$ rate was $100 \%$ (46 of 46 patients) like our study common side effects were hemoglobin drop (23\%), pruritus (19.6\%), and fatigue (15.2\%). Their study results were different from the results of the present study as our study listed 6 patients that stopped treatment due to adverse effects but the other study reported that all patients tolerated treatment well.

In agreement with the present study, Lawitz et al. [8] investigated the efficacy and safety of ombitasvir/paritaprevir/ritonavir in patients with hepatitis $\mathrm{C}$ virus genotype 4 infection and advanced kidney disease. They selected 65 patients including $50(76 \%)$ on dialysis and 15 (23\%) had compensated cirrhosis. They reported that SVR12 rate was 95\% (63/66); 3 patients discontinued treatment due to adverse events. Seventy-three percent (27/37) of patients receiving RBV had adverse events leading to RBV dose modification.

Another study, the results of which came similar to ours, is the study in which Mekky et al. [9] investigated the efficacy of ombitasvir/paritaprevir/ritonavir with ribavirin in the management of HCV genotype 4 and endstage kidney disease study which enrolled 110 patients. As regards SVR12, it was 96\% in HD and 91.4\% in nonHD patients. Treatment failure was observed in 6 patients. There were no reported serious adverse events. Anemia was observed in $66.6 \%$ in HD group and in $31.4 \%$ in non-HD group.

The study by El Kassas et al. [10] observed high rates for the use of ombitasvir/paritaprevir/ritonavir containing regimens study which included 325 patients (age, $47.63 \pm 12.63$ years); SVR12 was attained by $100 \%$ of patients who received OBV/rPTV/RBV as assessed by modified intention to treat analysis. In concordance with the present study, they found that there was a significant improvement of baseline alanine aminotransferase and aspartate aminotransferase. The most common reported adverse effects were anemia, fatigue, and elevated indirect bilirubin four patients stopped treatment at week 4 .
In contrast to our study, Said et al. [11] investigated ritonavir-boosted paritaprevir and ombitasvir plus ribavirin and 171 patients were included. All included patients reached the end of treatment with no treatment discontinuations. The overall end of treatment response was 100\%; 16 patients required blood transfusions.

The study by Yarass et al. [12] was different from the results of the present study as they reported that all 25 patients well tolerated the treatment regimen. Serious side effects causing treatment interruption were not observed. But their study agreed with the present study as they reported that the most frequent side effects were fatigue and itching. In accordance with the present results of the current study, a significant decrease in the level of serum alanine transaminase from 16.6 to $8.7 \mathrm{U} / \mathrm{l}$ after treatment was observed. This study enrolled 25 hemodialysisdependent patients; they found that there was no difference in serum albumin levels. The mean serum bilirubin levels increased from 0.49 to $0.56 \mathrm{mg} / \mathrm{dL}$ after treatment.

To study the efficacy of paritaprevir/ritonavir/ombitasvir plus dasabuvir regimen in the treatment of chronic hepatitis $C$ infection in patients with severe renal impairment and end-stage renal disease. Sperl et al. [13] enrolled 23 patients; SVR12 rate was $100 \%$. Unlike our study, none of the patients presented with a significant decrease in hemoglobin level during the treatment period. The most frequent adverse events were nausea, hypotension, and diarrhea. Four patients presented with a serious adverse event unrelated to the antiviral drugs (salmonellosis, non-functional kidney graft rejection, early gastric cancer, renal cyst infection). Concomitant medication had to be modified with the treatment initiation in 10 out of $23(43.5 \%)$ patients (calcium channel blockers, ACE inhibitors, statins, diuretics); four patients required further adjustment of antihypertensive drugs. Our study listed that no patients required dose adjustment of their medications.

In concordance with the present study, Atsukawa et al. [14] investigated the efficacy and safety of ombitasvir/ paritaprevir/ritonavir and ribavirin for chronic hepatitis patients in 94 patients. In agreement with the current study, they found that SVR were $97.9 \%$. Only two patients failed to achieve SVR. The median ALT levels decreased significantly after treatment. The hemoglobin levels decreased significantly during the treatment period, the most frequent adverse event was anemia (20.2\%; 19/94 patients) and pruritus.

In agreement to our study, Liu et al. [15] assessed effectiveness and safety of paritaprevir/ritonavir/ombitasvir. One hundred and three patients were enrolled in the study. One patient prematurely discontinued treatment due to hepatic decompensation, 23 patients complained of fatigue, 23 patients had nausea, 14 had pruritus, and 9 patients had dropped hemoglobin level. 
Abad et al. [16] observed sustained viral response to the combination of ombitasvir/paritaprevir/ritonavir. Thirty-five patients with genotypes 1 and 4 were treated with that DAA regimen. Sustained viral response was achieved in $100 \%$ of patients. Adverse effects were negligible, and no patient had to discontinue treatment. The most significant side effect was anemia, which led to a significant increase in the dose of erythropoiesisstimulating agents. Anemia was more marked in patients receiving ribavirin. No patients required transfusions.

Atsukawa et al. [17] studied efficacy and safety of ombitasvir/paritaprevir/ritonavir in dialysis patients with chronic hepatitis C. The study enrolled 31 patients and end-oftreatment response SVR12 were 93.5\%, while our study reported that SVR12 at hemodialysis group was $96.0 \%$ and at normal group was $100 \%$. The incidence of adverse events was $35.5 \%$. One discontinued the treatment. The most common adverse effect was pruritus (6.5\%), while our study reported that $12 \%$ of patients stopped treatment and the most common adverse effect was hemoglobin drop.

Another study, the results of which came similar to ours, is the study in which Pockros et al. [18] studied the efficacy of direct-acting antiviral combination for patients with hepatitis C. Study sample included 20 patients completed 12 weeks of treatment. Eighteen of the 20 patients achieved SVR, one patient died after the end of the treatment (unrelated to the treatment) and 1 relapse accounted. Adverse events were primarily mild or moderate, and no patient discontinued treatment due to an adverse effect. Four patients experienced serious adverse effects all were considered unrelated to treatment. Ribavirin therapy was interrupted in 9 patients due to anemia. No blood transfusions were needed in contrast to our study in which patients needed blood transfusion. Most patients experienced side effects, the majority of which were mild or moderate in severity. No patient discontinued DAAs due to adverse effects. In agreement to our study, the most common side effects were anemia (45\%), fatigue (35\%), diarrhea (25\%), and nausea (25\%).

Arai et al. [19] studied efficacy and safety of ombitasvir/paritaprevir/ritonavir combination therapy for genotype $1 \mathrm{~b}$ chronic hepatitis $\mathrm{C}$ patients complicated with chronic kidney disease; their study included 54 patients with impaired renal functions and 181 patients with normal renal functions. They concluded that only one patient among normal renal function group had increased in his serum creatinine level. This comes in agreement with our study that found that there is no effect of ombitasvir/paritaprevir/ritonavir on serum creatinine level during the course of treatment.

\section{Conclusion}

From the result of the present study, we concluded that ombitasvir, paritaprevir, and ritonavir are considered a safe and effective in treatment of HCV infection in patients on regular hemodialysis.

\section{Abbreviations}

FDA: Food and Drug Administration; HCV: Hepatitis C virus; NCCVH: National Committee for Control of Viral Hepatitis; SVR: Sustained virological response; DAAs: Direct-acting antivirals; PK: Pharmacokinetic; NS5A: Nonstructural protein 5A; RBV: Ribavirin; HD: Hemodialysis; ALT: Alanine aminotransferase; AST: Aspartate aminotrasferase; HBsAg: Hepatitis B surface antigen; AFP: Alpha fetoprotein; HCV PCR: Hepatitis C virus polymerase chain reaction; HbA1c: Glycosylated hemoglobin; CBC: Complete blood count; INR: International normalized ratio; IQR: Interquartile range; ANOVA: Analysis of variance; ACE: Angiotensin converting enzyme

\section{Acknowledgements}

Not applicable.

\section{Authors' contributions}

NMT and WAA selected the patients from hemodialysis units at Ain Shams University Hospitals and made the design for the study. AME and OAA contributed to follow-up of the patients at the Center of National Committee for Control of Viral Hepatitis [NCCVH] at Ain Shams University Hospital and analysis and interpretation of data. SME contributed to data collection. All authors provided critical feedback and helped shape the research, analysis, and manuscript. All authors have read and approved the manuscript.

\section{Funding}

The funders had no role in the study design, data collection and analysis, decision to publish, or preparation of the manuscript.

\section{Availability of data and materials}

The authors confirm that the data supporting the finding of this study are available within the article.

\section{Ethics approval and consent to participate}

This study was performed in accordance with the ethical standards of Ain Shams University Research Committee and with the 1964 Helsinki

Declaration and its later amendments or comparable ethical standards. Ethics committees reference number, 00017585.

A written informed consent was obtained from all individual participants included in the study.

\section{Consent for publication}

Informed consent to publish patient's data was signed by all participants prior to the beginning of the research.

\section{Competing interests}

The authors declare that they have no competing interests.

\section{Author details}

${ }^{1}$ Department of Internal Medicine and Nephrology, Faculty of Medicine, Ain Shams University, Ramsis 38 Street, Abassia, Cairo 11211, Egypt. ${ }^{2}$ Department of Internal Medicine and Gastroenterology, Faculty of Medicine, Ain Shams University, Cairo, Egypt.

Received: 19 March 2020 Accepted: 18 January 2021

Published online: 27 January 2021

\section{References}

1. Gower E, Estes C, Blach S et al (2014) Global epidemiology and genotype distribution of the hepatitis $C$ virus infection. Journal of Hepatology 61(1): S45-S57. https://doi.org/10.1016/j.jhep.2014.07.027

2. Gomaa A, Allam N, Elsharkway A et al (2017) Hepatitis C infection in Egypt: prevalence, impact and management strategies. Hepatic Medicine: Evidence and Research 9:17. https://doi.org/10.2147/HMER.S113681

3. McConachie SM, Wilhelm SM, Kale-Pradhan PB (2016) New direct-acting antivirals in hepatitis $C$ therapy: a review of sofosbuvir, ledipasvir, daclatasvir, simeprevir, paritaprevir, ombitasvir and dasabuvir. Expert Rev Clin Pharmacol 9(2):287-302 
4. Feld JJ, Kowdley KV, Coakley E et al (2014) Treatment of HCV with ABT-450/ r-ombitasvir and dasabuvir with ribavirin. N Engl J Med 370(17):1594-1603. https://doi.org/10.1056/NEJMoa1315722

5. American Association for the study of Liver Disease/Infectious Disease Society of America/ International Antiviral Society (2016) Recommendations for testing, managing, and treating hepatitis $C$ virus.

6. Omran D, Alboraie M, Zayed RA et al (2018) Towards hepatitis C virus elimination: Egyptian experience, achievements and limitations. World J Gastroenterol 24(38):4330-4340. https://doi.org/10.3748/wjg.v24.i38.4330

7. Liu CH, Shih YL, Yang SS et al (2019) Paritaprevir/ritonavir, ombitasvir plus dasabuvir for East-Asian non-cirrhotic hepatitis C virus genotype $1 \mathrm{~b}$ patients receiving hemodialysis. Journal of Gastroenterology and Hepatology 34(11): 1977-1983. https://doi.org/10.1111/jgh.14672

8. Lawitz E, Makara M, Akarca US et al (2019) Efficacy and safety of ombitasvir, paritaprevir, and ritonavir in an open-label study of patients with genotype $1 \mathrm{~b}$ chronic hepatitis $\mathrm{C}$ virus infection with and without cirrhosis. Gastroenterology 149(4):971-980

9. Mekky MA, Abdel-Malek MO, Osman HA et al (2019) Efficacy of ombitasvir/ paritaprevir/ritonavir/ribavirin in management of HCV genotype 4 and endstage kidney disease. Clinics and research in hepatology and gastroenterology 43(1):82-87. https://doi.org/10.1016/j.clinre.2018.08.003

10. El Kassas M, Alboraie M, Omar H et al (2019) High success rates for the use of ombitasvir/paritaprevir/ritonavir containing regimens in treatment of naive and experienced chronic hepatitis C genotype 4: real world results. J Med Virol. https://doi.org/10.1002/jmv.25478

11. Said M, Omar H, Soliman Z et al (2019) Ritonavir-boosted paritaprevir, ombitasvir plus ribavirin could improve eGFR in patients with renal impairment and HCV: an Egyptian cohort. Expert Review of Gastroenterology \& Hepatology 13(1):89-93. https://doi.org/10.1080/ 17474124.2019 .1544070

12. Yaraş S, Üçbilek E, Özdoğan $O$ et al (2019) Real-life results of treatment with ombitasvir, paritaprevir, dasabuvir, and ritonavir combination in patients with chronic renal failure infected with HCV in Turkey. Turk J Gastroenterol 30(4):331

13. Sperl J, Kreidlova M, Merta D et al (2018) Paritaprevir/ritonavir/ombitasvir plus dasabuvir regimen in the treatment of genotype 1 chronic hepatitis $C$ infection in patients with severe renal impairment and end-stage renal disease: a real-life cohort. Kidney Blood Press Res 43(2):594-605. https://doi. org/10.1159/000488965

14. Atsukawa M, Tsubota A, Koushima $Y$ et al (2018) Efficacy and safety of ombitasvir/paritaprevir/ritonavir and ribavirin for chronic hepatitis patients infected with genotype 2a in Japan. Hepatolo Res. 2(3):55-61. https://doi. org/10.1111/hepr.13292

15. Liu CH, Liu CJ, Su TH et al (2018) Real-world effectiveness and safety of paritaprevir/ritonavir, ombitasvir, and dasabuvir with or without ribavirin for patients with chronic hepatitis C virus genotype $1 \mathrm{~b}$ infection in Taiwan. J Gastroenterol Hepatol. 33(3):710-717. https://doi.org/10.1111/jgh.13912

16. Abad S, Vega A, Hernández E et al (2017) Universal sustained viral response to the combination of ombitasvir/paritaprevir/ritonavir and dasabuvir with/ without ribavirin in patients on hemodialysis infected with hepatitis $\mathrm{C}$ virus genotypes 1 and 4. Am J Nephrol 45(3):267-272. https://doi.org/10.1159/ 000454819

17. Atsukawa M, Tsubota A, Koushima Y et al (2017) Efficacy and safety of ombitasvir/paritaprevir/ritonavir in dialysis patients with genotype $1 \mathrm{~b}$ chronic hepatitis C. Hepatology Research 47(13):1429-1437. https://doi.org/ 10.1111/hepr.12910

18. Pockros PJ, Reddy KR, Mantry PS et al (2016) Efficacy of direct-acting antiviral combination for patients with hepatitis $C$ virus genotype 1 infection and severe renal impairment or end-stage renal disease. Gastroenterology 150(7):1590-1598. https://doi.org/10.1053/j.gastro.2016.02. 078

19. Arai T, Atsukawa M, Tsubota A et al (2018) Efficacy and safety of ombitasvir/ paritaprevir/ritonavir combination therapy for genotype $1 \mathrm{~b}$ chronic hepatitis C patients complicated with chronic kidney disease. Hepatol Res 48(7):549555. https://doi.org/10.1111/hepr.13058

\section{Publisher's Note}

Springer Nature remains neutral with regard to jurisdictional claims in published maps and institutional affiliations.

\section{Submit your manuscript to a SpringerOpen ${ }^{\circ}$ journal and benefit from:}

- Convenient online submission

- Rigorous peer review

- Open access: articles freely available online

- High visibility within the field

- Retaining the copyright to your article

Submit your next manuscript at $\boldsymbol{\nabla}$ springeropen.com 